\title{
International Economic Conflict and Its Analysis under Economic Globalization
}

\author{
Yinghan Liu, a \\ ${ }^{1}$ Chongqing College of Electronic Engineering, China, 400331 \\ aliuyinghan_lynn@163.com
}

Keywords: Economic globalization; International economy; Conflict

\begin{abstract}
The rapid development of economy makes the development of globalized economy accelerating continually. In order to alleviate more and more fierce international conflict and promote the health and scientific development of global economy, it is indispensable to own the support from international economic background. The only route is to alleviate international conflict and avoid international contradiction so as to establish a fair international economic competitive system, shorten the gap of economic development level among countries and promote the life quality of global human. This paper makes a detailed description for the international economic conflict under economic globalization.

In modern society, globalization is all around the social life as well as the economic field. The trade contact and economic relation among countries also is strengthening gradually. They are not only in a mutual cooperation but also in a mutual restriction. We can say that the globalized world economy is the inevitable result of social development. However, the realization of this process still needs a very long time. Therefore, we also can say that the globalized economic development is full of opposition and contradiction. In order to maintain its own interest, each country makes various conflicts interweaved together, which has not only affect the relations among countries severely, but also adverse to the economic development of whole world.
\end{abstract}

\section{International Economic Conflict under Current Economic Globalization}

At present, the international economic conflict under economic globalization is mainly reflected in the following aspects. First, we are lack of a global macroscopic adjustment and control. The recovery and rapid development of global market economy makes that the global resources are allocated mainly based on the market mechanism. Therefore, the role of market mechanism is fully highlighted. However, it is important that everything has two sides. The market mechanism also has some disadvantage, which mainly is reflected in a certain hysteresis and spontaneity. Nowadays, the global connection becomes close increasingly. An inappreciable error will affect the global economy, and then cause a chain react. However, as the three large international economic organizations currently responsible for global macroeconomic regulation and control, their role is not given full play. Their ability to regulate and control the global economy is not high. Secondly, the new protectionism existing widely and the economic environment with fiercer competition make each country to adjust their own trade policy so as to better maintain their own interest. Finally, some contradiction exists between the new regionalism and the multilateral coordination mechanism. The rapid development of regional economy has provided favorable opportunity for the new regionalism whose core principle is the regional interest is above all. Their focus is the interest of their region, which brings about a certain difficulty for the effective implementation of multilateral coordination mechanism and not conducive to the effective solving of international economic conflict.

\section{Efficient Approach to Alleviate International Economic Conflict under Globalized Economy}

In order to obtain a long-term interest, each country is adopting the efficient approach to alleviate the international economic conflict, specifically including the following aspects: face the 
conflict with a right attitude, establish a scientific international economic legal system, and give priority to the regional integrated economy. The details are as follows:

Face the Conflict with a Right Attitude. Each country should face the jurisdiction conflict and non-jurisdiction conflict of its own country and other countries with a right attitude. Take conflict facing as starting point to improve the own coping capacity to solve the conflict and further face the international economic conflict with a right attitude, which also is the efficient approach to alleviate the such conflict. Based on this, the country should actively make the coping approach to solve the conflict. Analyze and research the international economic conflict to deeply get its nature. Carry out an effective communication and consultation with other countries, and make a reasonable concession so as to find the approach to solve the conflict within the scope of jurisdiction. Take the concession in jurisdiction right as the approach to reasonably avoid the international economic conflict.

Establish a Scientific International Economic Legal System. The rapid development of economy makes the economic globalization in an inevitable trend. Therefore, the integration of world economy also is imperative. Under the new international economic environment, it can be regarded as the one of most efficient approaches to establish the scientific international economic measures so as to alleviate the international economic conflict. Make each country to join orderly through making the scientific and reasonable rule, which provides a powerful guarantee for the health development of global economy. This shows that to establish a scientific international economic legal system has the strategic significance for alleviating the international economic conflict. Although a lot of disputes have arisen in the international economic law in recent years, we believe that the international economic legal system must be able to play its due role, namely effectively alleviating the conflict and contradiction in the international economy in the future if we perfect it continually to ensure its scientificity and rationality. But, it needs the joint efforts of each country to establish a perfect international economic legal system, not only their unanimous opinion but also the legal adaptability evaluation made by them. In order to avoid the conflict, the education for each country should be intensified to enhance their comprehension so as to create a good international environment and lay a good environmental foundation for effectively solving the international economic conflict.

Give Priority to the Regional Integrated Economy. The development of globalized economy is a very slow process. The main reason is that it must be supported by the mutual cooperation among countries. Consequently, this process must reflect the principle of justice and equity so as to avoid the occurrence of secretly controlling activities of each country for its own interest and realize the effect of true advantages of economic globalization. Meanwhile, reduce the possibility of economic conflict through a diversified cooperation.

\section{Conclusion}

In a word, anything will not have a favorable wind all the way. We should face it with an active and right attitude. Although the competitive conflict among countries is inevitable, each country should observe the international order and perform its own responsibilities and obligations so as to establish a good international economic environment. Only in this way can we realize the multilateral interest, provide an outpouring power for the sustainable development of country, and lay a good foundation for improving the living standard of human.

\section{References}

[1] D. Xu, B. Xiao: International Economic Conflict and Its Solution under Economic Globalization. Jiangsu Social Sciences, 2010, (02):49-50.

[2] Y.Y. Deng: International Economic Conflict and Its Measures under Economic Globalization. China Business \& Trade, 2014, (28):108-109.

[3] X.Q. Wang: International Economic Conflict and Countermeasure Research under Economic 
Globalization. Northern Economy and Trade, 2014, (03):60.

[4] Speech of J.P. Xi at the opening ceremony of the Asia-Pacific Economic Co-operation CEO Summit. People's Daily, 2014-11-10(A02):12.13.

[5] W. Liu, J. Su: China's Macro Regulation under "New Normal". Economic Science, 2014, (04):12.

[6] C.J. Liu, B. Yu and Z.Y. Wu: Promote Economy to Smoothly Transit to New Normal. People's Daily, 2014-09-09(A07):15.

[7] Y. Ma: Analysis on Transformation of Macro-control Policy under New Economic Normal. Modern Economic Research, 2015(10):10-14

[8] L.N. Chai: Adapt to New Normal and Promote Development and Reform. Ningbo Economy: Finance and Economics Viewpoint,2015(4):10-11 